\section{DIGITALISATION IN MOBILITY}

The onset of digital or simulation or virtual engineering in the automotive world began decades ago. Continuous improvement has resulted in the developmental time and cost reduction between 20 to 35 $\%$ across the board due to simulation. The wastage of material during the product life cycle has reduced by $22 \%$, while the reliability and robustness has grown two fold in many of the systems. Decision makers are better informed for smarter decision making. Leveraging synergies and knowledge across the organisation and fraternity has simplified and is more efficient. Intercontinental sharing of data and information too is much simpler, efficient and faster.

Due to better communication tools there is significantly more transparency and trust between teams. Better project management has resulted in opportune assigning of appropriate resources, time, and planning ramp ups/ ramp downs at the click of a button. Some OEMs have attempted to leverage digitalisation to target zero physical prototypes during the developmental cycles.

\section{EARLY DAYS}

Initially, simulation was introduced as Computer Aided Engineering for analysing stresses, system dynamics, computational fluid dynamics and thermal management. Advent of XIL (all "in-the-loop" systems) for electronics and embedded systems changed the playing field by replacing the laborious time consuming aspects of physical testing. Visual design engineering to develop concepts and styling of vehicles, exterior and interior, reduced the need of multiple clay models and CNC machine time.

This was followed by colour therapy to create the best ambience of interiors and human machine interfaces. On large screens, one can see full scale vehicle models and interfaces. Simulation is leveraged to optimise weight, layout of wiring and plumbing, component layouts, under hood and underbody air flow, road clearances, vehicle dynamics, crash and safety aspects, activation and response time of sensors, and a multitude of aspects.

The emphasis on creating real life operating conditions of the vehicle to ensure robustness and higher reliability, created test methods that simulated driver behaviour along with real world conditions in the lab and on test tracks. Virtual lab tools and processes have radically changed the way testing and development is being carried out.

\section{DIGITAL SIMULATION}

In order to reduce manufacturing time and costs the line set-up, mould flow analysis, work flows and shop layouts for

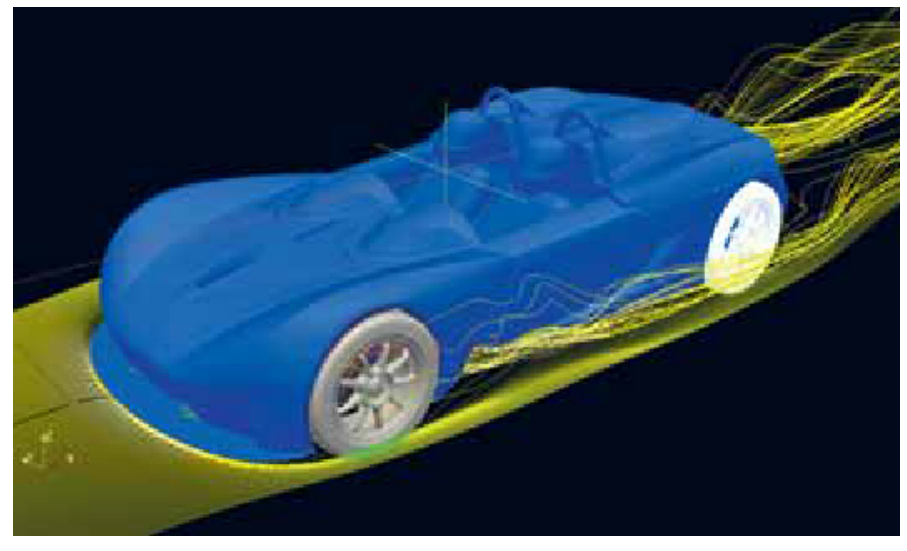

Simulation done on the Elemental Rp1

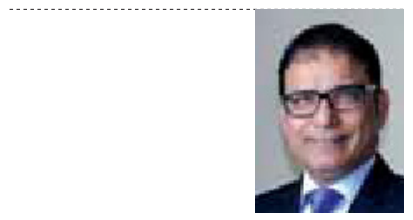

DR ARUN JAURA

European Advisory Committee,

SAE International, USA

quicker assembly are digitally simulated.

The assembly line ergonomics, robotic cells and the end of line assembly are simulated before actually building a plant or expanding the current infrastructure. These techniques have given a cost and time advantage to the industry, as transshipment equipment has become flexible and adaptable.

The customer interface experiences of buying a new vehicle and after sales service experiences are simulated after studying the ecosystem and the familial habits. Some OEMs have provided flexibility to consumers to handpick systems and order their vehicles online, follow the build on-line during assembly until its completion. Even the marketing campaigns are tuned to suit the digital environment and target specific customer segments in relevant geographies. The holistic approach is not limited to selling a vehicle but also adds simulating the financing aspects of value cycle, vehicle insurance, service reminders, auto updates of operating systems, recalls and the like.

Digitalisation of the automotive world has been a living process due to the codevelopment of tools and techniques, equipment and infrastructure. The focus on cost competitiveness, time to market, and the norms and regulations have been the biggest enablers in innovating digitalisation, day after day, in the automotive world. These have been augmented by skill development of a much smarter work force that has a proactive mind-set of customer centricity. Innovative partnerships between governments, academia and the industry are continuously seeing newer horizons of digitalisation across the global automotive footprint.

ftry Read this article on www.autotechreview.com 